(1)

CrossMark

\title{
Intensity and quality of exertional dyspnoea in patients with stable pulmonary hypertension
}

\author{
Athénaïs Boucly ${ }^{1,2,3}$, Capucine Morélot-Panzini ${ }^{4,5}$, Gilles Garcia (10) ${ }^{1,3}$, \\ Jason Weatherald (10 ${ }^{7,8}$, Xavier Jaïs ${ }^{1,2,3}$, Laurent Savale $\mathbb{1}^{1,2,3}$, \\ David Montani (101,2,3 Marc Humbert (10 ${ }^{1,2,3}$, Thomas Similowski ${ }^{4,5}$, \\ Olivier Sitbon (10) $1,2,3,10$ and Pierantonio Laveneziana ${ }^{4,9,10}$
}

@ERSpublications

The inflection in tidal volume relative to ventilation marks the onset of a large increase in dyspnoea intensity and in the selection frequency of unsatisfied inspiration as the predominant dyspnoea descriptor in patients with stable pulmonary hypertension http://bit.ly/2JRA5bI

Cite this article as: Boucly A, Morélot-Panzini C, Garcia G, et al. Intensity and quality of exertional dyspnoea in patients with stable pulmonary hypertension. Eur Respir J 2020; 55: 1802108 [https://doi.org/ 10.1183/13993003.02108-2018].

ABSTRACT Dynamic hyperinflation is observed during exercise in $60 \%$ of patients with clinically stable pulmonary arterial hypertension (PAH) and chronic thromboembolic pulmonary hypertension (CTEPH), intensifying exertional dyspnoea. The impact of dynamic changes in respiratory mechanics during exercise on qualitative dimensions of dyspnoea in these patients has not been evaluated.

26 patients (PAH $n=17$; CTEPH $n=9$ ) performed an incremental symptom-limited cycle exercise test. Minute ventilation $\left(V_{\mathrm{E}}^{\prime}\right)$, breathing pattern, operating lung volumes and dyspnoea intensity were assessed throughout exercise. Dyspnoea quality was serially assessed during exercise using a three-item questionnaire (dyspnoea descriptors). The inflection point of tidal volume $\left(V_{\mathrm{T}}\right)$ relative to $V_{\mathrm{E}}^{\prime}$ was determined for each incremental test. Changes in inspiratory capacity during exercise defined two groups of patients: hyperinflators $(65 \%)$ and non-hyperinflators (35\%). Multidimensional characterisation of dyspnoea was performed after exercise using the Multidimensional Dyspnea Profile.

In hyperinflators, inspiratory capacity decreased progressively throughout exercise by $0.36 \mathrm{~L}$, while remaining stable in non-hyperinflators. The "work/effort" descriptor was most frequently selected throughout exercise in both types of patients (65\% of all responses). At the $V_{\mathrm{T}} / V_{\mathrm{E}}^{\prime}$ inflection, work/effort plateaued while "unsatisfied inspiration" descriptors became selected predominantly only in hyperinflators (77\% of all responses). In the affective domain, the emotion most frequently associated with dyspnoea was anxiety.

In pulmonary hypertension patients who develop hyperinflation during exercise, dyspnoea descriptors referring to unsatisfied inspiration become predominant following the $V_{\mathrm{T}} / V_{\mathrm{E}}^{\prime}$ inflection. As these descriptors are generally associated with more negative emotional experiences, delaying or preventing the $V_{\mathrm{T}} / V_{\mathrm{E}}^{\prime}$ inflection may have important implications for symptom management in patients with pulmonary hypertension. 


\section{Introduction}

Exertional dyspnoea is the commonest presenting complaint in patients with idiopathic pulmonary arterial hypertension (PAH) and chronic thromboembolic pulmonary hypertension (CTEPH) [1-3]. Despite considerable research, its origins and underlying mechanisms have not been fully elucidated $[1,3]$. The symptom progresses inexorably as the disease advances, impoverishing quality of life [1-3]. Previous studies have largely focused on the cardiovascular determinants of exertional dyspnoea [4-6]. However, mechanical anomalies of respiration, such as dynamic lung hyperinflation, have recently been shown to occur in some PAH and CTEPH patients during exercise [7-9] and are likely to aggravate exertional dyspnoea in these patients $[8,9]$.

In terms of lung volumes, patients with stable pulmonary hypertension $(\mathrm{PH})$ may either deflate (decrease their end-expiratory lung volume (EELV)) or progressively hyperinflate (increase their EELV) during exercise [7-9]. This may also occur in patients with asthma [10] and chronic obstructive pulmonary disease (COPD) $[11,12]$. The nature of these exercise-related changes in lung volumes is associated with the terms that patient uses to describe their dyspnoea. Patients who deflate predominantly describe their dyspnoea as increased "work/effort" of breathing at the limit of tolerance during exercise. In those who hyperinflate, both increased work/effort of breathing and "unsatisfied inspiration" are reported at the limit of tolerance during exercise $[8,10]$. It has previously been postulated that the increased intensity of work/ effort may reflect the conscious appreciation of increased central neural command output (and the concurrent inspiratory muscle contractile effort relative to maximum required) to keep pace with the increasing metabolic and ventilatory demands imposed by exercise $[9,10,13-16]$. Conversely, the growing mismatch between the increase in the central neural command to the ventilatory musculature and the blunted respiratory mechanical and/or muscular response caused by dynamic hyperinflation and/or critical mechanical constraints of tidal volume $\left(V_{\mathrm{T}}\right)$ expansion has been hypothesised to play a part in the neurophysiological basis of the sensation of unsatisfied inspiration $[9,10,13]$.

It has been shown that during exercise in COPD [11, 16-18], and more recently in asthma [10], an inflection in the $V_{\mathrm{T}}$ response occurs when inspiratory reserve volume (IRV) becomes critically reduced. This is not always the case in some sedentary [16] and asthmatic [10] subjects in whom this $V_{\mathrm{T}}$ inflection may occur on exertion when IRV is largely preserved. When this inflection in the $V_{\mathrm{T}}$ response is reached at a critical IRV, dyspnoea intensity rises more impressively and quasi-vertically, and unsatisfied inspiration becomes the prominent qualitative descriptor. This inflection can easily be detected in healthy sedentary subjects [16], in athletes [19] and in most COPD [11, 16-18] and asthma patients [10] by examining 1) the contributions of $V_{\mathrm{T}}$ and respiratory frequency to the ventilatory response $\left(V_{\mathrm{E}}^{\prime}\right)$ to exercise by plotting $V_{\mathrm{T}}$ as a function of $V_{\mathrm{E}}^{\prime}\left(V_{\mathrm{T}} / V_{\mathrm{E}}^{\prime}\right.$ relationship) and 2) analysing the relationship between the nature of the dyspnoea and the IRV. The practical implication of this is that the $V_{\mathrm{T}}$ inflection occurring at a critically reduced IRV marks a reproducible mechanical event with important sensory consequences during exercise $[10,11,16]$. We hypothesised that the same mechanical and sensory phenomena would occur in $\mathrm{PH}$ patients exhibiting exercise-related hyperinflation, regardless of the aetiology of their PAH or CTEPH. In contrast, $\mathrm{PH}$ patients who do not hyperinflate during exercise would not exhibit similar mechanical and sensory changes but would behave more like healthy subjects [16] or some asthmatics who do not hyperinflate on exertion [10].

Characterising how patients describe their dyspnoea when they reach the limit of their exercise tolerance is clinically relevant, because the different types of dyspnoea have different emotional implications $[1,3]$. For instance, in the experimental setting, the sensation of unsatisfied inspiration is much more unpleasant than the excessive work/effort sensation at a given sensory intensity [20]. Thus, therapeutic interventions

Affiliations: 'Université Paris-Sud, Faculté de Médecine, Université Paris-Saclay, Le Kremlin-Bicêtre, France. ${ }^{2}$ AP-HP, Hôpital Bicêtre, Service de Pneumologie et Soins Intensifs, Le Kremlin-Bicêtre, France. ${ }^{3}$ INSERM UMR_S 999, Hôpital Marie Lannelongue, Le Plessis Robinson, France. ${ }^{4}$ Sorbonne Université, INSERM, UMRS1158 Neurophysiologie Respiratoire Expérimentale et Clinique, Paris, France. ${ }^{5}$ AP-HP, Groupe Hospitalier Pitié-Salpêtrière Charles Foix, Service de Pneumologie, Médecine Intensive et Réanimation, Département R3S, Paris, France. ${ }^{6}$ APHP, Hôpital Bicêtre, Service de Physiologie, Le Kremlin-Bicêtre, France. ${ }^{7}$ University of Calgary, Dept of Medicine, Division of Respirology, Calgary, AB, Canada. ${ }^{8}$ Libin Cardiovascular Institute of Alberta, University of Calgary, Calgary, AB, Canada. ${ }^{9}$ AP-HP Sorbonne Université, Groupe Hospitalier Pitié-Salpêtrière Charles Foix, Service des Explorations Fonctionnelles de la Respiration, de l'Exercice et de la Dyspnée du Département Médico-Universitaire «APPROCHES», Paris, France. ${ }^{10}$ Both authors contributed equally and are both last authors.

Correspondence: Pierantonio Laveneziana, AP-HP Sorbonne Université, Groupe Hospitalier Pitié-Salpêtrière Charles Foix, Service des Explorations Fonctionnelles de la Respiration, de l'Exercice et de la Dyspnée, Département Médico-Universitaire «APPROCHES», Hôpitaux Universitaires Pitié-Salpêtrière, Tenon et SaintAntoine, 47-83 Boulevard de l'Hôpital, 75013, Paris, France. E-mail: pierantonio.lavenezianadaphp.fr 
that postpone the moment where $\mathrm{PH}$ patients shift from work/effort to unsatisfied inspiration could be of clinical interest.

\section{Materials and methods Study design}

We studied 26 nonsmoking consecutive patients with clinically stable PAH $(n=17)$ and incident CTEPH $(n=9)$ [21], diagnosed according to currently available practice guidelines [22, 23], with a normal body mass index and no evidence of obstructive ventilatory defect at resting spirometry [24]. This sample size estimation was based on dyspnoea intensity ratings measured previously in our laboratory $[8,9]$ and the following assumptions: a standard deviation of $\sim 1.0$ unit, a difference of $\sim 1.5$ units measured at a standardised work rate during incremental cardiopulmonary cycle exercise testing (CPET), a two-sided test, $80 \%$ power and $\alpha=0.05$.

Patients were included in the study irrespective of the treatment received, if they had been clinically stable during the three preceding months, and if they had been scheduled for CPET within the framework of the standard clinical follow-up at our centre. The study consisted of two consecutive visits. At visit 1, patients performed a 6-min walk test $(6 \mathrm{MWT})$ in the morning, and a right heart catheterisation at rest, and during recumbent cycle exercise testing in the afternoon [25]. At visit 2, patients performed pulmonary function tests followed by incremental CPET $[8,26]$.

Patients with diseases other than $\mathrm{PH}$ were excluded from the study; subjects with dysfunctional breathing were also excluded.

The research was performed in accordance with the principles outlined in the Declaration of Helsinki. The subjects gave their informed consent to participate, and the study received the ethical committee approval of the institutional review board of the National Centre for Pulmonary Hypertension (DYSPNEE $\mathrm{H}_{\mathrm{T}}$ AP-ID-RCB: 2015-A01826-43).

\section{Procedures}

Pulmonary function tests were performed according to recommended standards [27-29]. Measurements were expressed as percentages of predicted normal values [30]. Procedures for conducting symptom-limited incremental CPET have been described previously [8, 26]. Briefly, symptom-limited incremental CPETs were conducted on an electrically braked cycle ergometer (Ergoline 100P mitBD; Medisoft, Sorinnes, Belgium) with a cardiopulmonary exercise testing system (Ergocard model E; Medisoft). The equipment was calibrated before each test. To ensure safety, oxygen saturation measured by pulse oximetry $\left(S_{\mathrm{pO} 2}\right)$, heart rate, cardiac rhythm and ST-segment changes and blood pressure (indirect sphygmomanometry) were evaluated at rest and throughout exercise testing. Breath-by-breath cardiopulmonary and metabolic data were collected at baseline and throughout exercise while subjects breathed through a mouthpiece with nasal passages occluded by a nose clip. All exercise tests consisted of a steady-state resting period of $6 \mathrm{~min}$ and a 3-min warm-up of unloaded pedalling followed by an incremental test in which the work rate (WR) was increased in 1-min intervals by increments of $10 \mathrm{~W}$ until the point of symptom limitation (peak exercise). Patients were instructed to maintain the pedalling rate between 50 and 70 revolutions per minute. Exercise variables were measured and averaged over the last $20 \mathrm{~s}$ of each minute and at peak exercise. Measurements of arterial partial pressure of carbon dioxide were obtained at rest and at peak exercise only in PAH patients. The physiological dead space to $V_{\mathrm{T}}$ ratio and the gradient between arterial and end-tidal carbon dioxide partial pressure were also calculated $[8,26]$. The intensity of dyspnoea and of leg discomfort were rated using the modified 10-point Borg scale [31] at rest, every minute during exercise and at peak exercise. Iso-WR and iso- $V_{\mathrm{E}}^{\prime}$ were defined as the highest equivalent exercise WR and exercise $V_{\mathrm{E}}^{\prime}$ achieved by all participants during all the tests.

\section{Indices of ventilatory constraint}

Operating lung volumes derived from inspiratory capacity manoeuvres, such as EELV, were measured at rest, every second minute during exercise and at the end of exercise, based on the assumption that total lung capacity (TLC) did not change significantly during the exercise, as previously demonstrated [8]. inspiratory capacity was used to track any decrease or increase in EELV (expressed as an absolute value) during exercise, as described previously $[11,26]$. Dynamic hyperinflation during exercise is now clearly defined as a decrease in inspiratory capacity from rest of $>150 \mathrm{~mL}$ at any time-point during exercise [26]. A critically low IRV was arbitrarily (although now universally accepted) defined as a reduction in the IRV to a minimum of $\sim 0.5 \mathrm{~L}$ (ranging from 0.4 to $0.6 \mathrm{~L}$ ), as described in COPD [11-13, 16-18]. Indices of ventilatory constraint, the /extent and the method of assessment of expiratory flow limitation and the inflection point of the $V_{\mathrm{T}} / V_{\mathrm{E}}^{\prime}$ relationship are described in detail in the supplementary material. 
Right heart catheterisation

Right heart catheterisation (RHC) with haemodynamic evaluation was performed at rest and during cycle ergometry exercise in the supine position, as described previously [32]. Details are available in the supplementary material.

\section{Evaluation of exercise-related symptoms}

Patients rated the intensity of "breathing discomfort" (dyspnoea) at rest, every minute throughout CPET and at peak CPET, using the Borg 0-10 category-ratio scale [31]. The Borg 0-10 category-ratio scale was also used for assessing the intensity of "breathing discomfort" (dyspnoea) during the 6MWT (rest and peak) and during exercise RHC (rest and peak). At the moment of the Borg scale evaluation during CPET, $6 \mathrm{MWT}$ and exercise RHC, patients were also asked to select the phrase that best described their breathing from a list of three items [11]: "my breathing requires more work and effort" (work/effort); "I cannot get enough air in" (unsatisfied inspiration); and "my chest feels tight" (chest tightness). Patients were allowed to select multiple phrases if all were equally applicable. The former two descriptors were collected for primary analysis, while the latter was used as a control symptom that was not expected to be selected very often. More details about the dyspnoea descriptors can be found in the supplementary material. Immediately after each type of exercise (CPET, 6MWT and haemodynamic cycle ergometry exercise), subjects completed the Multidimensional Dyspnea Profile (MDP) focusing on the last $30 \mathrm{~s}$ of each type of exercise [33]. MDP data were used to describe the nature of discomfort produced by the stimulus and to determine whether that description changed according to exercise modality $[33,34]$. More details on the MDP are available in the supplementary material.

\section{Statistical analysis}

Data were expressed as mean $\pm \mathrm{SD}$ for normally distributed variables or medians $(25-75 \%$ interquartile range (IQR)) for non-normally distributed variables (Kolmogorov-Smirnov test). For variables with normal distribution, a t-test was used. For non-normally distributed variables, a non-parametric test (Mann-Whitney rank test) was used. McNemar's exact test was used to assess the statistical significance of changes of selection frequency of dyspnoea descriptors before and after the $V_{\mathrm{T}}$ inflection. Comparisons between $\mathrm{PH}$-hyperinflators and $\mathrm{PH}$-non-hyperinflators were performed at rest, at common standardised exercise WR (20 W: iso-WR 1; $40 \mathrm{~W}$ : iso-WR 2), at iso- $V_{\mathrm{E}}^{\prime}$, at the $V_{\mathrm{T}}$ inflection and at peak exercise using Friedman repeated measures ANOVA on ranks. Metabolic, cardioventilatory and perceptual responses at iso- $V_{\mathrm{E}}^{\prime}$ were calculated by linear interpolation between adjacent measurement points for each subject. All statistical procedures were performed using Intercooled Stata 8.0 for Windows (Stata, College Station, TX, USA) and SPSS 18.0 for Windows (SPSS, Chicago IL, USA). Differences were considered significant when the probability of a Type I error was $<0.05$.

\section{Results}

The patients' characteristics, resting pulmonary function testing and the physiological and perceptual responses to CPET in PAH and CTEPH are summarised in tables 1 and 2. More details are available in the supplementary material.

\section{Identification of two subgroups of PH patients}

Based on rest-to-peak changes in inspiratory capacity, 17 patients $(65 \% ; n=11$ PAH and $n=6$ CTEPH) exhibited dynamic hyperinflation during exercise (hyperinflator group, inspiratory capacity $-0.36 \mathrm{~L}$ ). The remaining nine patients (35\%; $n=6 \mathrm{PAH}$ and $\mathrm{n}=3 \mathrm{CTEPH})$ did not (non-hyperinflator group, inspiratory capacity $+0.01 \mathrm{~L})(\mathrm{p}<0.001$; figure 1 and table 3$)$. Both hyperinflator and non-hyperinflator patients were stable on therapy with satisfactory haemodynamic and clinical status, as demonstrated by cardiac output at rest, right atrial pressure, New York Heart Association functional class and 6-min walk distance (table 3). Patient characteristics, resting pulmonary function and the physiological and perceptual responses to CPET of the two groups are compared in table 3 and table 4.

Subjects in the hyperinflator group presented with greater dynamic expiratory flow limitation than their non-hyperinflator counterparts (at $20 \mathrm{~W} 25 \pm 5 \%$ versus $5 \pm 10 \%, \mathrm{p}=0.0005$ ), as suggested by the encroachment of $V_{\mathrm{T}}$ on the maximal expiratory flow-volume envelope (details on methods can be found in the supplementary material). The percentage of $V_{\mathrm{T}}$ being expiratory flow-limited was consistently higher in hyperinflator group than non-hyperinflators at any stage of cycle exercise $(p<0.05)$. Of interest, a strong correlation was found between expiratory flow limitation and inspiratory capacity at $V_{\mathrm{T}}$ inflection in the hyperinflator group ( $\mathrm{r}=-0.80, \mathrm{p}=0.04)$. More details can be found in the supplementary material. 


\begin{tabular}{|c|c|}
\hline Female/male & $16 / 10$ \\
\hline Age years & $45(30-52)$ \\
\hline BMI $\mathrm{kg} \cdot \mathrm{m}^{-2}$ & $25.7 \pm 5.0$ \\
\hline \multicolumn{2}{|l|}{ Pulmonary hypertension aetiology } \\
\hline PAH (idiopathic/heritable/HIV-associated) & $17(10 / 5 / 2)$ \\
\hline CTEPH & 9 \\
\hline Newly diagnosed cases & 9 \\
\hline Duration of prevalent PH years & $4.4(1.6-9.7)$ \\
\hline \multicolumn{2}{|l|}{ Haemodynamics } \\
\hline Right atrial pressure mmHg & $7 \pm 3$ \\
\hline Mean pulmonary artery pressure mmHg & $49 \pm 14$ \\
\hline Pulmonary artery wedge pressure $\mathrm{mmHg}$ & $9 \pm 3$ \\
\hline Cardiac output L. $\min ^{-1}$ & $5.7 \pm 1.8$ \\
\hline Cardiac index $\mathrm{L} \cdot \mathrm{min}^{-1} \cdot \mathrm{m}^{-2}$ & $3.2 \pm 0.9$ \\
\hline Pulmonary vascular resistance Wood units & $7 \pm 3$ \\
\hline Mixed venous oxygen saturation \% & $67 \pm 8$ \\
\hline \multicolumn{2}{|l|}{ PAH-targeted therapy } \\
\hline None & 10 \\
\hline Calcium channel blockers & 2 \\
\hline Oral monotherapy & 3 \\
\hline Dual oral combination therapy & 3 \\
\hline PDE-5 inhibitor + i.v. epoprostenol & 1 \\
\hline Triple combination therapy + i.v. epoprostenol & 7 \\
\hline NYHA functional class I/II/III/IV & $10 / 9 / 7 / 0$ \\
\hline 6MWD m & $517 \pm 101$ \\
\hline \multicolumn{2}{|l|}{ Lung function test } \\
\hline $\mathrm{FEV}_{1} / \mathrm{VC} \%$ & $82 \pm 10$ \\
\hline FEV $_{1} \%$ pred & $96 \pm 18$ \\
\hline TLC \% pred & $94 \pm 16$ \\
\hline$D_{\text {Lco }} \%$ pred & $65 \pm 15$ \\
\hline$K_{\text {co }} \%$ pred & $76 \pm 20$ \\
\hline$P_{\mathrm{aO}_{2}} \mathrm{mmHg}$ & $80 \pm 13$ \\
\hline$P_{\mathrm{aCO}_{2}} \mathrm{mmHg}$ & $33 \pm 4$ \\
\hline
\end{tabular}

Data are presented as $n$, median (interquartile range) or mean \pm SD. BMI: body mass index; PAH: pulmonary arterial hypertension; $\mathrm{CTEPH}$ : chronic thromboembolic pulmonary hypertension; $\mathrm{PH}$ : pulmonary hypertension; PDE: phosphodiesterase; NYHA: New York Heart Association; 6MWD: 6-min walk distance; $\mathrm{FEV}_{1}$ : forced expiratory volume in $1 \mathrm{~s}$; VC: vital capacity; TLC: total lung capacity; $D_{\mathrm{Lco}}$ : diffusing capacity of the lung for carbon monoxide; $K_{\mathrm{CO}}$ : carbon monoxide transfer coefficient; $P_{\mathrm{aO}_{2}}$ : arterial partial pressure of oxygen; $P_{\mathrm{aCO}}$ : arterial partial pressure of carbon dioxide.

\section{$\mathrm{V}_{T}$ inflection and dyspnoea descriptors}

A notable inflection in the $V_{\mathrm{T}} / V_{\mathrm{E}}^{\prime}$ relationship occurred in both hyperinflators and non-hyperinflators, regardless of $\mathrm{PH}$ aetiology. The average exercise $\mathrm{WR}$ at the $V_{\mathrm{T}}$ inflection was $66 \pm 25 \mathrm{~W}$ in hyperinflators versus $56 \pm 30 \mathrm{~W}$ in non-hyperinflators $(\mathrm{p}=0.19)$. The evolution of dyspnoea descriptors during CPET in $\mathrm{PH}$ as whole group is shown in figure 2. At iso-WR 1,35\% of patients (nine out of 26) selected work/ effort, 15\% (four out of 26) selected difficult/unsatisfied inspiration, and the remaining 13 (50\%) patients did not select anything. At the $V_{\mathrm{T}}$ inflection, $65 \%$ of patients (17 out of 26 ) selected work/effort, $23 \%$ (six out of 26) selected difficult/unsatisfied inspiration and one patient selected chest tightness. At peak, 19\% of patients (five out of 26) selected work/effort, 77\% (20 out of 26) selected difficult/unsatisfied inspiration and one patient selected chest tightness. Figure $3 \mathrm{a}$ and $\mathrm{b}$ describes the evolution of dyspnoea descriptors during CPET in hyperinflator and non-hyperinflator patients.

When coupling the specific dyspnoea descriptor selection to the response of $V_{\mathrm{T}}$ before, at and after its inflection on an individual basis, we found a clear and consistent change in the selection of dyspnoea descriptor in hyperinflator patients: these patients reached their $V_{\mathrm{T}}$ inflection at a critically low IRV of $0.53 \pm 0.22 \mathrm{~L}$ compared with the remaining non-hyperinflator patients, who reached their $V_{\mathrm{T}}$ inflection at a preserved IRV of $0.81 \pm 0.32 \mathrm{~L}$ (figure 1). Hyperinflators notably selected work/effort as the most representative qualitative dyspnoea descriptor of their dyspnoea until the $V_{\mathrm{T}}$ inflection, then consistently changed their qualitative dyspnoea descriptor from work/effort to difficult/unsatisfied inspiration (McNemar test $\mathrm{p}=0.025)$ from $V_{\mathrm{T}}$ inflection to peak exercise. In contrast, non-hyperinflators continued to select work/effort throughout exercise, with no change between $V_{\mathrm{T}}$ inflection and peak exercise. 
TABLE 2 Physiological and perceptual responses to cardiopulmonary exercise testing in pulmonary arterial hypertension (PAH) and chronic thromboembolic pulmonary hypertension (CTEPH) patients

\begin{tabular}{|c|c|c|c|c|c|c|c|c|}
\hline & \multicolumn{2}{|c|}{ Rest } & \multicolumn{2}{|c|}{ iso-WR 1} & \multicolumn{2}{|c|}{ iso-WR 2} & \multicolumn{2}{|c|}{ Peak } \\
\hline Work rate $\mathrm{W}$ & & & $20 \pm 0$ & $20 \pm 0$ & $40 \pm 0$ & $40 \pm 0$ & $104 \pm 36^{*}$ & $78 \pm 27$ \\
\hline$V^{\prime} \mathrm{CO}_{2} L \cdot \min ^{-1}$ & $0.28 \pm 0.09$ & $0.32 \pm 0.08$ & $0.52 \pm 0.13$ & $0.57 \pm 0.15$ & $0.72 \pm 0.13$ & $0.74 \pm 0.13$ & $1.58 \pm 0.41 *$ & $1.19 \pm 0.50$ \\
\hline$V_{E}^{\prime} L \cdot \min ^{-1}$ & $15.0 \pm 4.2^{*}$ & $24.2 \pm 8.7$ & $23.8 \pm 6.7^{*}$ & $37.3 \pm 8.7$ & $31.6 \pm 7.5^{*}$ & $48.8 \pm 10.2$ & $75.3 \pm 23.2$ & $77.2 \pm 13.4$ \\
\hline Respiratory rate breaths $\cdot \min ^{-1}$ & $19 \pm 4^{*}$ & $22 \pm 5$ & $24 \pm 7$ & $31 \pm 13^{9}$ & $25 \pm 7 *$ & $32 \pm 9$ & $41 \pm 7$ & $42 \pm 10$ \\
\hline Dyspnoea Borg units & $0.4 \pm 0.7$ & $0.3 \pm 0.7$ & $0.9 \pm 1.1^{*}$ & $2.9 \pm 2.0$ & $1.9 \pm 1.6^{*}$ & $4.2 \pm 2.5$ & $6.7 \pm 1.5$ & $7.4 \pm 1.7$ \\
\hline$P_{\mathrm{aO}_{2}} \mathrm{mmHg}$ & $84.1 \pm 12.1 *$ & $69.9 \pm 8.4$ & & & & & $76.9 \pm 15.9 *$ & $57.3 \pm 11.5$ \\
\hline$P_{\mathrm{aCO}_{2}} \mathrm{mmHg}$ & $31.1 \pm 4.1^{\#}$ & $33.6 \pm 5.2$ & & & & & $31.3 \pm 3.4$ & $32.8 \pm 13.0$ \\
\hline$P_{\mathrm{A}-\mathrm{aO}}, \mathrm{mmHg}$ & $25.9 \pm 11.5^{*}$ & $46.0 \pm 10.0$ & & & & & $45.8 \pm 16.9 *$ & $62.2 \pm 10.6$ \\
\hline$V_{\mathrm{D}} / V_{\mathrm{T}}^{2}$ & $0.43 \pm 0.10^{*}$ & $0.57 \pm 0.13$ & & & & & $0.49 \pm 0.08 *$ & $0.64 \pm 0.10$ \\
\hline
\end{tabular}

Data are presented as mean \pm SD. iso-WR 1: common standardised exercise work-rate (WR) of $20 \mathrm{~W}$; iso-WR 2: common standardised exercise WR of $40 \mathrm{~W} ; V^{\prime} \mathrm{O}_{2}$ : oxygen uptake; $V^{\prime} \mathrm{CO}_{2}$ : carbon dioxide production; $V_{\mathrm{E}}^{\prime}$ : minute ventilation; $V_{\mathrm{T}}$ : tidal volume; IC: inspiratory capacity; $P_{\mathrm{aO}}$ : arterial partial pressure of oxygen; $P_{\mathrm{acO}}$ : arterial partial pressure of carbon dioxide; $P_{\mathrm{A}-\mathrm{aO}}$ : alveolar-arterial oxygen partial pressure difference; $V_{D}$ : dead space volume. ${ }^{*}: \mathrm{p}<0.05$, PAH versus CTEPH at the same measurement point. ${ }^{\text {\# }}: \mathrm{p}=0.06 ;{ }^{{ }^{7}}: \mathrm{p}=0.09 ;^{+}: \mathrm{p}=0.07$.

In addition, we observed that the $V_{\mathrm{T}}$ inflection coincided with an inflection in the dyspnoea/IRV relationships in the hyperinflator group. This means that the relationship between dyspnoea intensity and IRV was biphasic in the hyperinflator group: reported dyspnoea gradually increased up to 4.4 Borg units until the critical IRV corresponding to the $V_{\mathrm{T}}$ inflection was reached, then impressively and quasi-vertically increased by 3 Borg units to reach the symptom-limited end-point of exercise (7.2 Borg units) (figure 1). The relationship between the selection frequency of difficult/unsatisfied inspiration and IRV was found to be biphasic in the hyperinflator group.

In contrast, in the non-hyperinflator group, dyspnoea increased linearly with time and $V_{\mathrm{E}}^{\prime}$ up to 3.3 Borg units to reach the $V_{\mathrm{T}}$ inflection, then increased by 3 Borg units from the $V_{\mathrm{T}}$ inflection to peak exercise.

MDP

Results of the MDP (arbitrary units (a.u.)) are expressed as median (IQR). In the MDP items relating to unpleasantness or discomfort (A1 scale) recorded immediately after CPET (table 4), hyperinflators rated unpleasantness or discomfort higher (8 (7-9) a.u.) than non-hyperinflators (5 (0-8) a.u.; p=0.037); 65\% of hyperinflators compared with $11 \%$ of non-hyperinflators $(\mathrm{p}=0.025)$ reported "not enough air, smothering or hunger for air" on the sensory dimension items of the MDP (table 4). Of note, "not enough air, smothering or hunger for air" was associated with greater anxiety (4.4 a.u., data not shown in table 4) in $65 \%$ of hyperinflators compared with $11 \%$ of non-hyperinflators ( 2 a.u.) during CPET ( $\mathrm{p}=0.025)$, with no statistical difference between patients with and without hyperinflation under conditions such as 6MWT and RHC. A similar pattern of sensory and affective responses was obtained when MDP was administered immediately after 6MWT and RHC (table 4).

\section{Discussion}

The main findings of this study are 1) a notable $V_{\mathrm{T}}$ inflection occurred in both hyperinflator and non-hyperinflator patients, regardless of $\mathrm{PH}$ aetiology; 2) the attainment of a $V_{\mathrm{T}}$ inflection at a critically low dynamic IRV marks an important mechanical event during exercise in $\mathrm{PH}$ patients who hyperinflate and has major sensory consequences. At that moment, dyspnoea intensity escalates sharply and there is a transition in the dominant qualitative descriptor choice from work/effort to unsatisfied inspiration; 3 ) the sense of breathing work/effort is the predominant description of respiratory discomfort in $\mathrm{PH}$ patients who do not hyperinflate and who still present with a $V_{\mathrm{T}}$ inflection but at a preserved IRV during exercise; 4) the MDP revealed that the sensation of unsatisfied inspiration was far more unpleasant than the excessive work/effort sensation, and that the emotion most frequently associated with dyspnoea was anxiety; and 5) the evolution of the intensity and quality of exertional dyspnoea seems to be independent of the $\mathrm{PH}$ aetiology and rather reflects the mechanical constraints and operating lung volume evolution on individual basis. 
a)

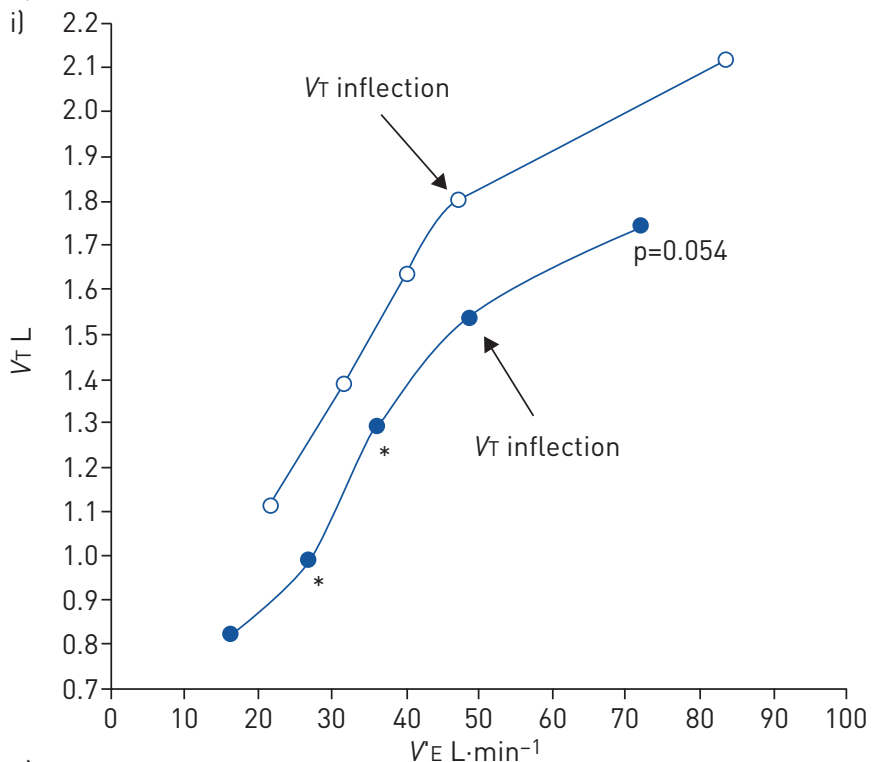

b)

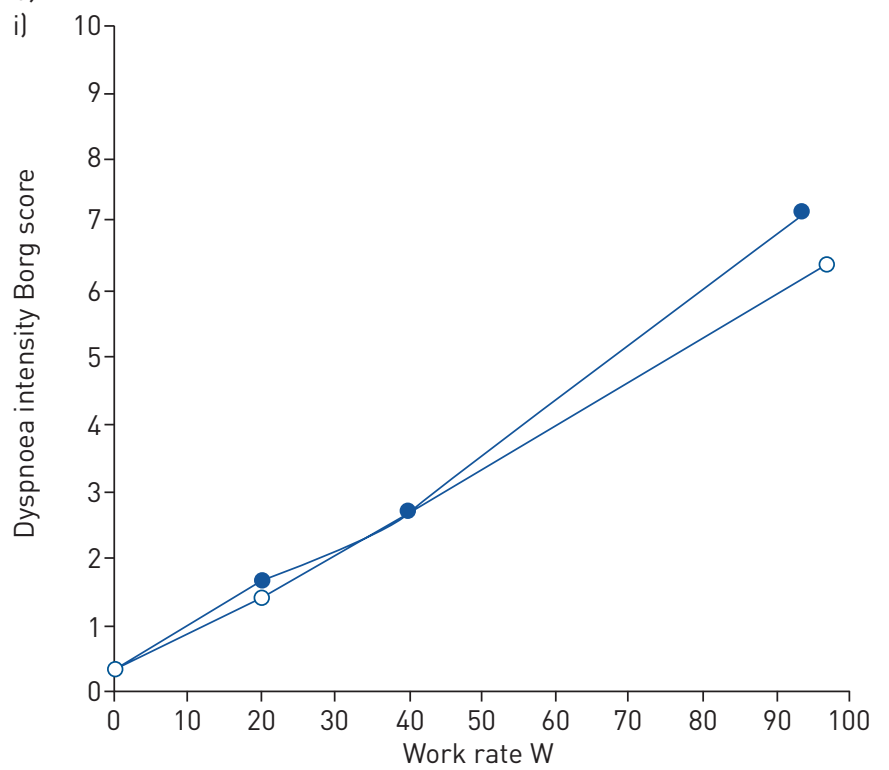

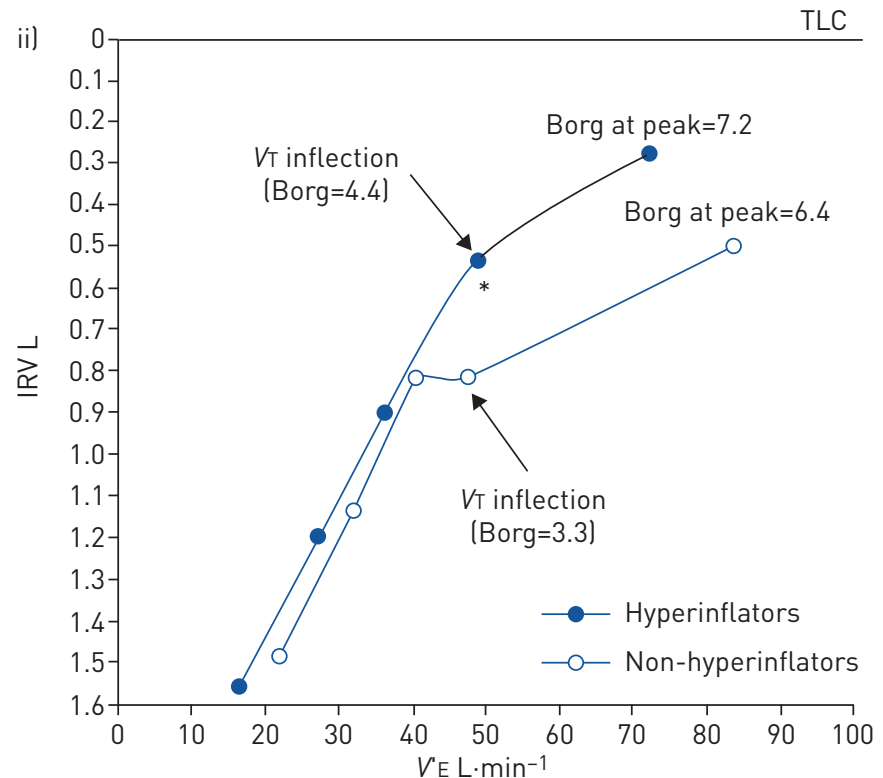

ii)

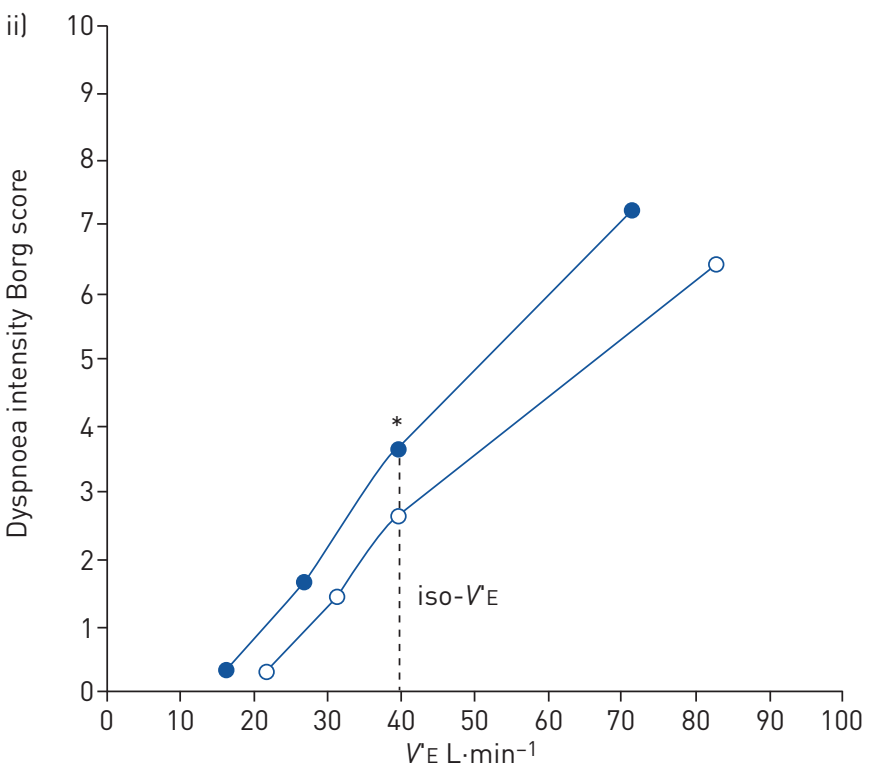

FIGURE 1 a) Evolution (change) in i) tidal volume $\left(V_{T}\right)$ and ii) inspiratory reserve volume (IRV) from rest to peak exercise is shown in response to increasing minute ventilation $\left(V^{\prime}\right)$ during symptom-limited incremental cycle exercise in patients with pulmonary hypertension who hyperinflate (decrease their inspiratory capacity: hyperinflators) and deflate (increase their inspiratory capacity: non-hyperinflators). Data are presented as mean at rest, at $20 \mathrm{~W}$ (iso-WR 1), at $40 \mathrm{~W}$ (iso-WR 2), at the $V_{\mathrm{T}}$ inflection point and at peak exercise. ${ }^{*}$ : p<0.05 significant difference between groups at a given time-point. Arrows indicate the $V_{T}$ inflection point in each group. Note that hyperinflators reached their $V_{T}$ inflection at a critically low IRV of $0.53 \mathrm{~L}$ compared with the remaining non-hyperinflators who reached their $V_{\mathrm{T}}$ inflection at a preserved IRV of $0.81 \mathrm{~L}$. Hyperinflators reported that dyspnoea gradually increased up to 4.4 Borg units until the critical IRV corresponding to the $V_{\mathrm{T}}$ inflection point was reached, then impressively and quasi-vertically increased by 3 Borg units to reach the symptom-limited end-point of exercise (7.2 Borg units). In contrast, in the non-hyperinflator group, dyspnoea increased linearly with $V^{\prime}$ up to 3.3 Borg units to reach the $V_{T}$ inflection point, then increased by 3 Borg units from the $V_{\mathrm{T}}$ inflection point to peak exercise. b) Exertional dyspnoea intensity (Borg score) is shown i) in response to increasing work rate increasing $V_{E}^{\prime}$ and ii) during symptom-limited incremental cycle exercise in patients with pulmonary hypertension who hyperinflate and deflate. Data are presented as mean at rest, at $20 \mathrm{~W}$ (iso-WR 1), at $40 \mathrm{~W}$ (iso-WR 2) and at peak exercise (i) and as mean at rest, at $20 \mathrm{~W}$ (iso-WR 1), at iso- $V^{\prime}$ E and at peak exercise (ii). *: p<0.05 significant difference between groups at a given time-point. TLC: total lung capacity.

\section{Ventilatory response and constraints}

This study is the first to show that a notable inflection in the $V_{\mathrm{T}}$ response occurs during exercise in hyperinflators with stable $\mathrm{PH}$, as happens in healthy unfit subjects [16, 35-38], athletes [19] and in patients with COPD [11, 17] and chronic heart failure [39]. At this point, the $V_{\mathrm{T}}$ began to plateau with no further significant expansion until the end of exercise. Of note, in non-hyperinflators, the $V_{\mathrm{T}}$ inflection did occur, but at a preserved IRV (table 3). This behaviour seems to be crucial to sensory perception. When this 
TABLE 3 Comparisons between hyperinflator and non-hyperinflator pulmonary hypertension patients

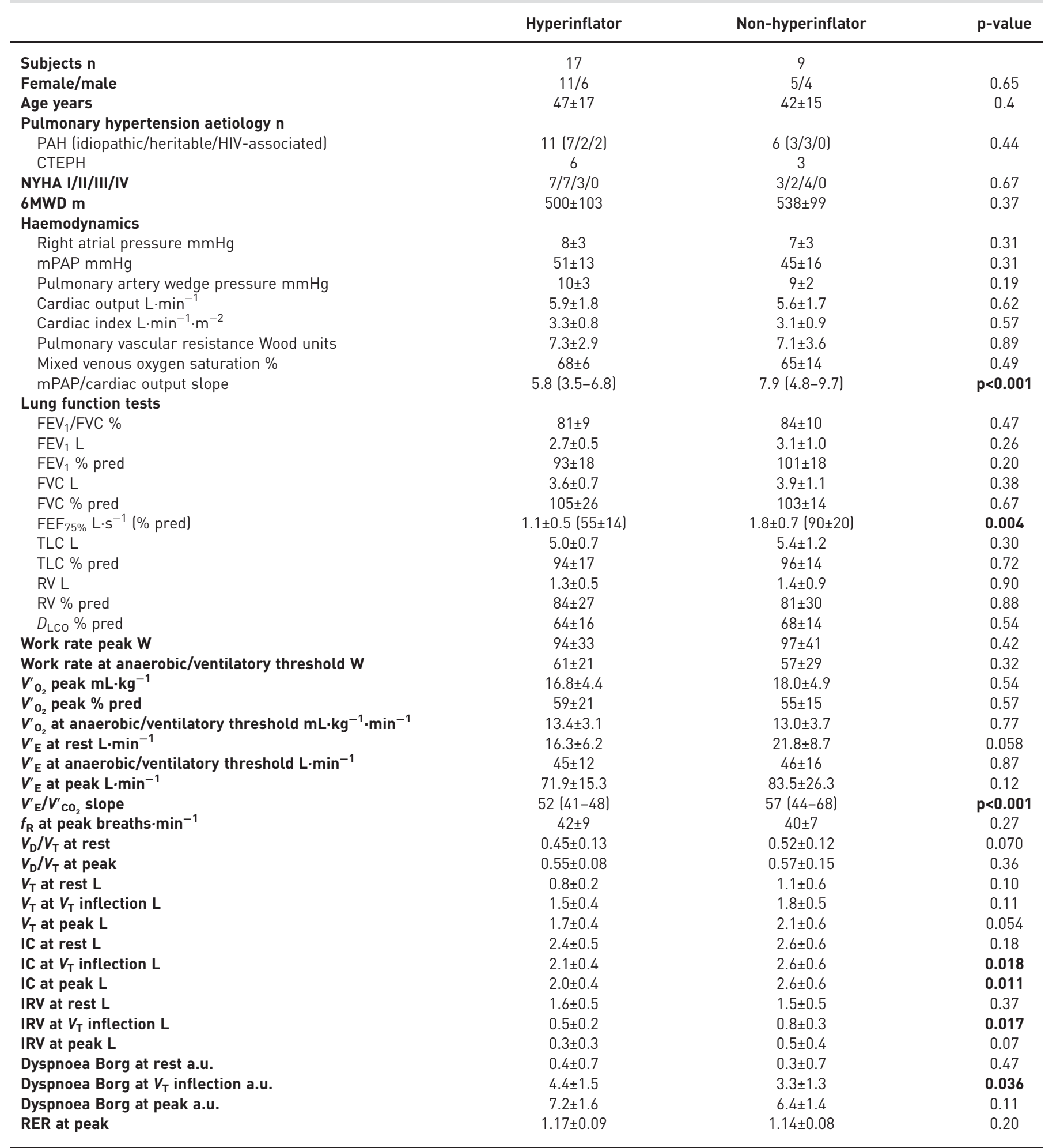

Results are presented as mean \pm SD or median (interquartile range), unless otherwise stated. Bold type represents statistical significance. PAH: pulmonary arterial hypertension; CTEPH: chronic thromboembolic pulmonary hypertension; NYHA: New York Heart Association; 6MWD: 6-min walk distance; mPAP: mean pulmonary artery pressure; $\mathrm{FEV}_{1}$ : forced expiratory volume in $1 \mathrm{~s} ; \mathrm{FVC}$ : forced vital capacity; $\mathrm{FEF}_{75 \%}$ : forced expiratory flow at $75 \%$ of the FVC; TLC: total lung capacity; RV: residual volume; $D_{\text {Lco: }}$ diffusing capacity of the lung for carbon monoxide; $V^{\prime}{ }_{O_{2}}$ : oxygen uptake; $V_{E}^{\prime}$ : minute ventilation; $V^{\prime}{ }_{\mathrm{CO}_{2}}$ : carbon dioxide output; $f_{\mathrm{R}}$ : respiratory rate; $V_{\mathrm{D}}$ : dead space volume; $V_{\mathrm{T}}$ : tidal volume; IC: inspiratory capacity; IRV: inspiratory reserve volume; a.u.: arbitrary units; RER: respiratory exchange ratio. 
TABLE 4 Comparisons of Multidimensional Dyspnea Profile (MDP) in hyperinflator and non-hyperinflator pulmonary hypertension patients

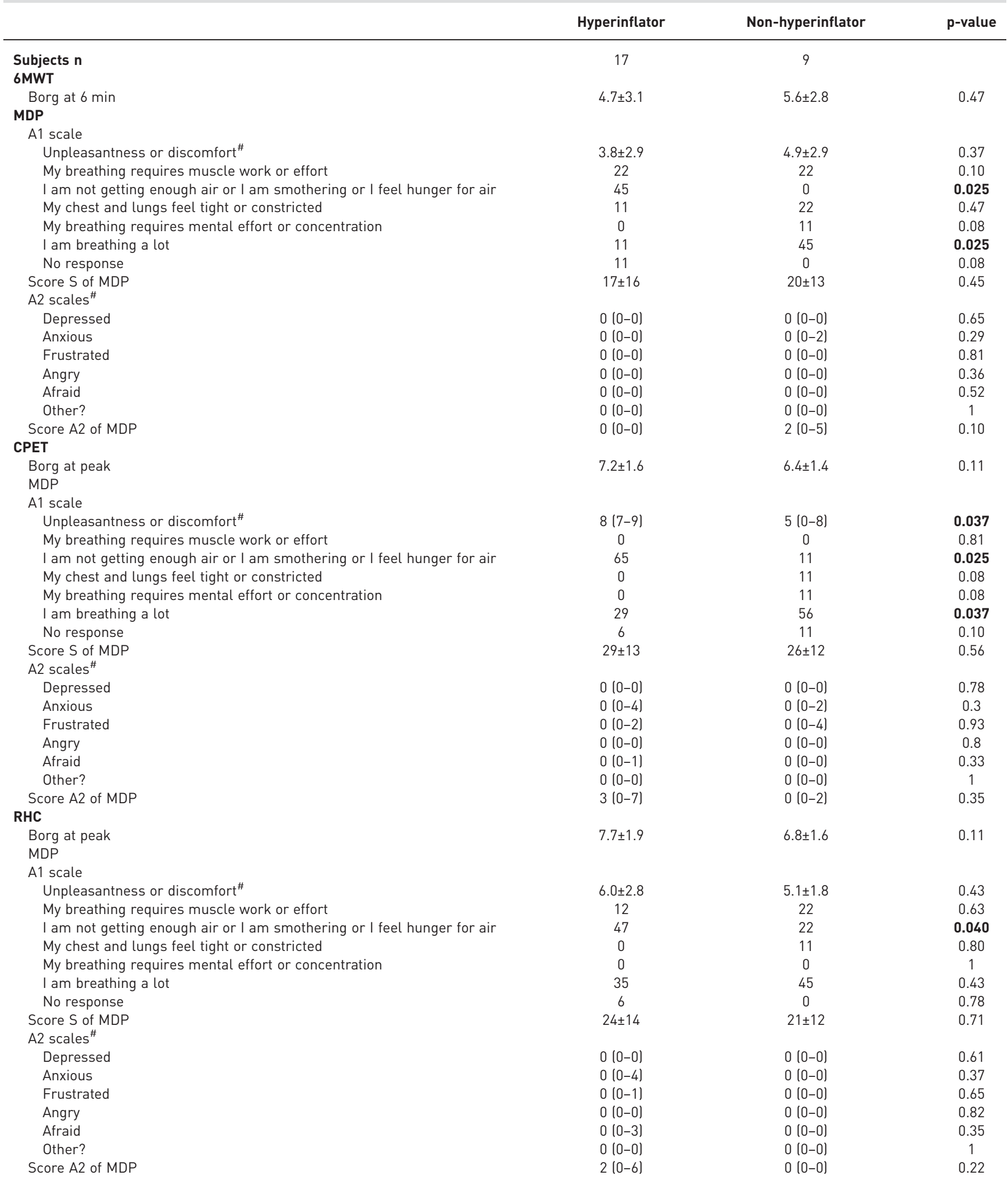

Data are presented as mean $\pm \mathrm{SD}, \%$ or median (interquartile range), unless otherwise stated. Bold type represents statistical significance. 6MWT: 6-min walk test; a.u.: arbitrary units; CPET: cardiopulmonary exercise testing; RHC: right heart catheterisation. ${ }^{\#}$ : 0-10 a.u. 


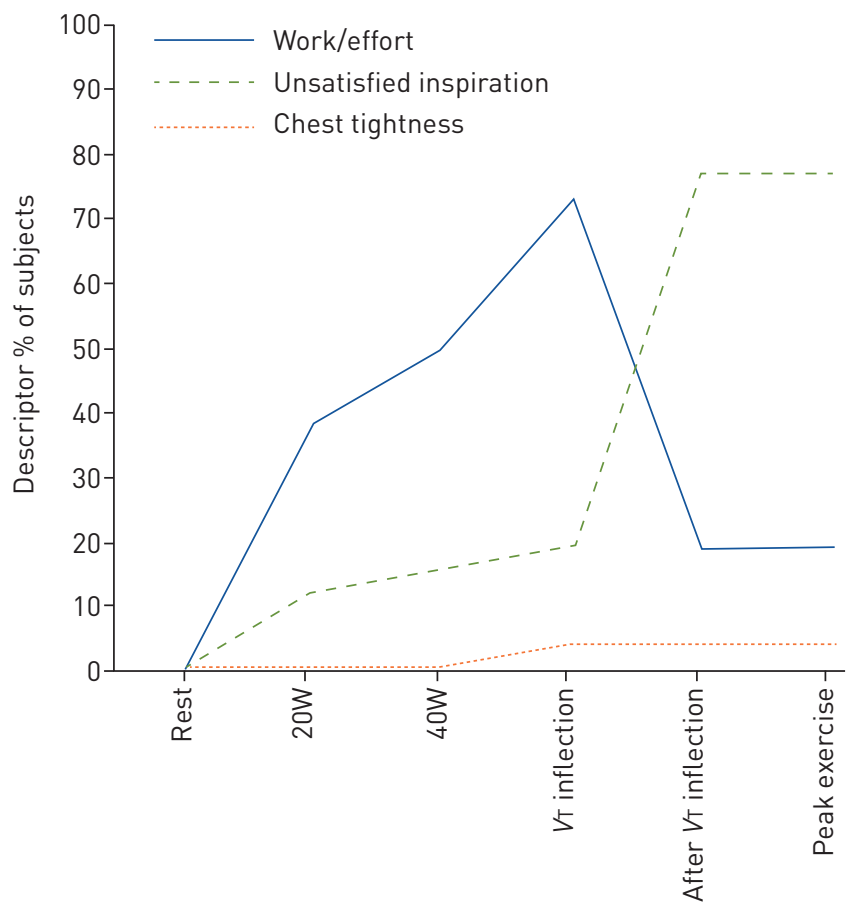

FIGURE 2 Selection frequency of the three descriptor phrases evaluated during symptom-limited incremental cycle exercise in patients with pulmonary hypertension as whole group $(n=26)$ : increased work and effort, unsatisfied inspiration and chest tightness. Data are presented as mean at rest, at $20 \mathrm{~W}$ (iso-work rate (WR) 1), at $40 \mathrm{~W}$ (iso-WR 2), at the tidal volume $\left(V_{T}\right)$ inflection point, after the $V_{T}$ inflection point and at peak exercise.

inflection occurred while the IRV was preserved, dyspnoea increased linearly with time and $V_{\mathrm{E}}^{\prime}$ and showed only a modest increase (by 3 Borg units) from the $V_{\mathrm{T}} / V_{\mathrm{E}}^{\prime}$ inflection to peak exercise. The sensation of breathing work/effort was the dominant dyspnoea descriptor selected throughout exercise (figure $3 \mathrm{~b}$ ), regardless of type and mode of exercise (CPET, 6MWT and haemodynamic cycle ergometry exercise) (supplementary figure E1). This is in line with our previous observations in asthmatic patients [10, 13] and healthy subjects at the termination of exercise $[14,16]$. This behaviour can be explained as follows: the greater inspiratory capacity observed at the $V_{\mathrm{T}}$ inflection in non-hyperinflators (figure 1) would have permitted ventilation at lung volumes well below the TLC, thus avoiding a critically low IRV and all the mechanical and sensory consequences associated with it. In these circumstances, it is not surprising that the sense of breathing work/effort was the predominant description of respiratory discomfort in non-hyperinflators during exercise.

In contrast, attainment of a critically low dynamic IRV at $V_{\mathrm{T}}$ inflection marked the point where dyspnoea intensity rose more impressively and quasi-vertically and difficult/unsatisfied inspiration increased steeply relative to work/effort only and exclusively in hyperinflators (figures 2 and $3 \mathrm{a}$ ). Before the $V_{\mathrm{T}}$ inflection, dyspnoea intensity rose linearly into the moderate range (Borg rating $\sim 4$ ) and hyperinflators were more likely to select work/effort and less likely to select the difficult/unsatisfied inspiration descriptor. After the $V_{\mathrm{T}}$ inflection, dyspnoea intensity rose more steeply to intolerable levels (mean Borg rating 7 "very severe" at peak) and difficult/unsatisfied inspiration was increasingly selected as the dominant qualitative descriptor (figure 3a).

The last point to highlight here is why some patients hyperinflated during exercise while others did not. Compared with non-hyperinflators, hyperinflators exhibited a consistent and uniform reduction of the maximal expiratory flow rates over the effort-independent portion of the maximal flow-volume curve (forced expiratory flow at $75 \%$ of the forced vital capacity $\left(\mathrm{FEF}_{75 \%}\right)$ ), while the $\mathrm{FEV}_{1} /$ vital capacity ratio, TLC and inspiratory capacity were preserved between the two groups (table 3). Whether these spirometric abnormalities truly reflect peripheral airways obstruction is still debated [8]. However, small airway dysfunction has previously been described in PAH [8] and suspected in CTEPH [40]; its mechanisms are poorly understood. Regardless of the mechanisms underlying the PH-related small airway dysfunction, the shape and limits of the maximal flow-volume curve in the tidal operating range (showing a reduction of $\mathrm{FEF}_{75 \%}$ ) mean that, in our hyperinflator patients (both $\mathrm{PAH}$ and $\mathrm{CTEPH}$ ), the operating $V_{\mathrm{T}}$ was positioned closer to residual volume than normally. As a result, our hyperinflator patients (both PAH and 

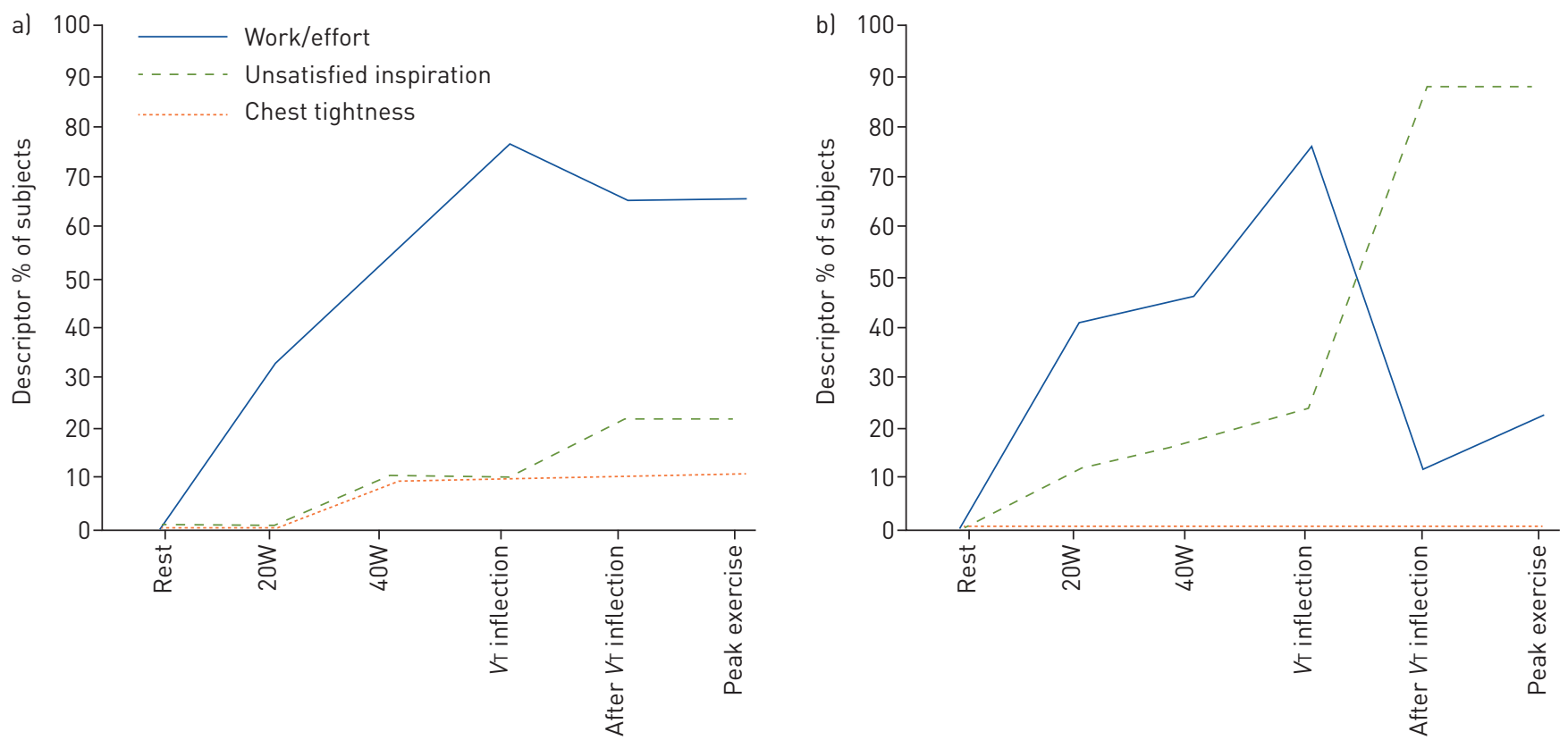

FIGURE 3 Selection frequency of the three descriptor phrases evaluated during symptom-limited incremental cycle exercise in patients with pulmonary hypertension (PH) who a) deflate (non-hyperinflators) and b) hyperinflate (hyperinflators) during exercise: increased work and effort, unsatisfied inspiration and chest tightness. Data are presented as mean at rest, at $20 \mathrm{~W}$ (iso-work rate (WR) 1), at 40 W (iso-WR 2), at the tidal volume $\left(V_{T}\right)$ inflection point, after the $V_{T}$ inflection point and at peak exercise.

CTEPH) had an increased propensity to expiratory flow limitation. Indeed, although hyperinflator patients (both $\mathrm{PAH}$ and $\mathrm{CTEPH}$ ) did not exhibit evident expiratory flow limitation during resting breathing, they encroached on their maximal expiratory flow reserve relatively early in exercise (at $20 \mathrm{~W}$ ). In fact, from $20 \mathrm{~W}$ to peak exercise, our hyperinflator patients (both PAH and CTEPH) were no more able to expand $V_{\mathrm{T}}$ by encroaching on the expiratory reserve volume due to the no longer available expiratory flow reserve at that lung volume (expiratory flow limitation was $25 \pm 5 \%$ in hyperinflators versus $5 \pm 10 \%$ in non-hyperinflators, $\mathrm{p}=0.0005)$. Of note, a strong correlation was found between expiratory flow limitation and inspiratory capacity at $V_{\mathrm{T}}$ inflection in hyperinflator group $(\mathrm{r}=-0.80, \mathrm{p}=0.04)$. As a consequence, $V_{\mathrm{T}}$ continued to increase only by encroaching on the IRV, and the inspiratory capacity decreased substantially (dynamic hyperinflation) in our hyperinflator patients (both PAH and CTEPH), under the condition of increased ventilatory demand. Therefore, even if resting inspiratory capacity is preserved in both PAH [8] and CTEPH [40] (as recently demonstrated by RICHTER et al. [40] in operable CTEPH pre- and post-pulmonary endarterectomy after excluding pulmonary diseases), its dynamic decrease during exercise may be attributed, at least in part, to the development of expiratory flow limitation, provided that TLC remains stable and respiratory muscle dysfunction does not develop during exercise, as previously ruled out in PAH patients $[8,9]$. Last, but not least, how and to what extent haemodynamics may have influenced dynamic hyperinflation and vice versa is difficult to ascertain; non-hyperinflators had a significantly steeper mean pulmonary artery pressure (mPAP)/cardiac output slope and $V_{\mathrm{E}}^{\prime} /$ carbon dioxide production $\left(V_{\mathrm{CO}_{2}}\right)$ slopes compared with hyperinflators (further detail can be found in table 3 and the supplementary material). This suggests (with a word of caution, of course) that dynamic hyperinflation, by increasing intrathoracic pressure and imposing mechanical constraints on $V_{\mathrm{T}}$ expansion, might have mitigated the rise in cardiac output, $\mathrm{mPAP}$ and $V_{\mathrm{E}}^{\prime}$ in hyperinflator patients (both $\mathrm{PAH}$ and $\mathrm{CTEPH}$ ), as recently demonstrated in COPD patients undergoing exercise [41, 42]. In addition, a steeper $V_{\mathrm{E}}^{\prime} / V_{\mathrm{CO}_{2}}$ slope (ventilatory inefficency) was recently found to be related to impaired right ventricular diastolic function in PAH [43]. Whether these recent and intriguing findings may add to the explanations already given for the differences in $\mathrm{mPAP} /$ cardiac output steepness observed between non-hyperinflator and hyperinflator PH patients in our study is difficult to say and further studies are needed to shed light upon these mechanisms.

\section{Work/effort and unsatisfied inspiration}

It seems that these major qualitative descriptors evolve separately throughout exercise and are strongly influenced by mechanical events such as the $V_{\mathrm{T}}$ inflection in hyperinflators. Before this inflection, the negative mechanical consequences of breathing at a higher lung volume (i.e. dynamic hyperinflation) may be 
initially counterbalanced by reduced resistive work, which attenuates the rise in the intensity of dyspnoea. The attendant acute mechanical loading early in exercise (up until the $V_{\mathrm{T}}$ inflection) may result in a relatively higher inspiratory effort than normal for a given force generated by the respiratory muscles $[11,18]$ and the qualitative sensation of work/effort may reflect the conscious appreciation of increased central motor command output under these circumstances.

In contrast, as IRV reaches a critical level at the $V_{\mathrm{T}}$ inflection (because of dynamic hyperinflation), little or no further $V_{\mathrm{T}}$ expansion is possible and dyspnoea intensity then rises steeply to intolerable levels. This blunted $V_{\mathrm{T}}$ displacement occurring as a result of dynamic hyperinflation in the face of progressive increases in central respiratory drive may be responsible, at least in part, for the perception of difficult/ unsatisfied inspiration in hyperinflators.

Although the precise mechanisms responsible for the critical reduction in IRV observed in hyperinflators has not been fully elucidated, the significant decrease in inspiratory capacity (i.e. dynamic hyperinflation) observed in this group appears to be the most plausible contributory factor. Regardless of mechanisms, the reduced inspiratory capacity observed in hyperinflators forces $V_{\mathrm{T}}$ to the upper non-compliant reaches of the respiratory system's pressure-volume relationship and negatively affects inspiratory muscle performance, which was not the case in non-hyperinflators. This may contribute directly or indirectly to the intensity and quality of dyspnoea in hyperinflators after the $V_{\mathrm{T}}$ inflection [44].

\section{MDP and its clinical relevance}

The MDP revealed that the sensation of unsatisfied inspiration was far more unpleasant than the excessive work/effort sensation, and corroborated the contention that in the affective domain, the emotion most frequently associated with dyspnoea was anxiety. Interestingly, the same pattern of response in terms of sensory and affective dimension/domain was found when the MDP was administered immediately after 6MWT and RHC (table 4).

Regardless of the mechanisms involved, it is important to emphasise that observing a change in dyspnoea description as the causative stimulus (here, exercise) persists can be clinically relevant. Experiments conducted in healthy subjects have shown that the unsatisfied inspiration family of descriptors of dyspnoea ("air hunger", "not enough air", "smothering", "suffocating") is associated with a more negative affect than work/effort even when the corresponding sensory intensity is identical [20]. Clinical studies based on the MDP suggest that air hunger is more often associated with anxiety and fear than "excessive/effort" [34, 45]. Therapeutic interventions can relieve dyspnoea by interfering mostly with its affective component [45]. In our study, hyperinflators had MDP subscores significantly different from non-hyperinflators: hyperinflators rated unpleasantness or discomfort higher than non-hyperinflators (table 3, p=0.037); among sensory dimension items, "not enough air, smothering or hunger for air", was reported in $65 \%$ of hyperinflators' responses compared with $11 \%$ of non-hyperinflators' responses $(\mathrm{p}=0.025)$. The emotion most frequently associated with "not enough air, smothering or hunger for air" was anxiety (4.4 a.u.) in 65\% of hyperinflators compared with $11 \%$ of non-hyperinflators (2 a.u.) during CPET, with no statistical difference between them under conditions such as $6 \mathrm{MWT}$ and RHC.

\section{The multifactorial origin of exertional dyspnoea in pulmonary hypertension}

Our results reinforce the previously documented notion that in clinical situations where lung mechanics are not an intuitive candidate to explain dyspnoea, dynamic hyperinflation-induced constraint of $V_{\mathrm{T}}$ expansion can play a significant role. This seems important from a therapeutic standpoint, because it opens up new horizons for research in the "multiaxial" treatment of dyspnoea. Any intervention that improves exertional dyspnoea should be beneficial even when this intervention is not directly related to the principal pathophysiological determinant of the disease [46]. This reasoning is supported by the observation that the relationship between dyspnoea intensity and the underlying disease's abnormalities is not linear, but rather exponential, especially in $\mathrm{PH}$. In other words, when a disease is already responsible for intense dyspnoea, a small additional deterioration directly or indirectly related to the disease (for example, abnormalities of respiratory mechanics) can make dyspnoea intolerable, and there is evidence that improving airway mechanics after acute administration of bronchodilators can ameliorate the condition of patients with chronic heart failure patients [47]. It follows, therefore, that a therapeutic intervention that effectively reduces dynamic hyperinflation, such as inhaled bronchodilators, should theoretically delay the appearance of the mechanical constraint of $V_{\mathrm{T}}$ expansion and the attendant dyspnoea during physical activity in selected patients with stable PH. An important clinical implication for symptom management in $\mathrm{PH}$ patients arises from our study: as the sensation of unsatisfied inspiration is more uncomfortable than work/effort and was generally associated with more negative emotional experiences such as anxiety in our study, it is fundamental not only to slow down the build-up of dyspnoea (intensity), but also to delay or prevent the moment (the $V_{\mathrm{T}} / V_{\mathrm{E}}^{\prime}$ inflection point) when the 
highly anxiogenic unsatisfied inspiration occurs. The last point to highlight here is the contention that the evolution of the intensity and quality of exertional dyspnoea seems to be largely independent of $\mathrm{PH}$ aetiology and rather reflects the mechanical constraints and operating volume history on individual basis.

\section{Limitations}

Our primary analysis of the qualitative dimensions of dyspnoea during exercise was confined to two descriptors based on our primary hypothesis on respiratory mechanical constraints during exercise in this population: other descriptors not included here may also be relevant to the complex experience of exertional dyspnoea in stable PH. The relatively small and heterogeneous sample size of the present study means that we must be circumspect in generalising our findings to the wider $\mathrm{PH}$ population. In addition, differences between the sexes in terms of respiratory mechanics and psychological impact might be relevant in the current study. Studies of the physiological mechanisms that also measure oesophageal pressure will be required to further elucidate the respiratory mechanics of exertional dyspnoea in $\mathrm{PH}$ patients.

Last but not least, we are aware that the issue as to whether dynamic hyperinflation is a cause of tachypnoea and anxiety or vice versa is not resolved in this study and should be clearly addressed in future studies. What is clear in our study is that there is absolutely no difference between hyperinflators and non-hyperinflators in terms of respiratory rate: hyperinflators are as much tachypnoeic as non-hyperinflators. Of note, we deliberately excluded patients with dysfunctional breathing. Concerning the link between anxiety, dyspnoea and dynamic hyperinflation, we can say that in some COPD studies (nothing in PH) dyspnoea is able to elicit or aggravate anxiety, but we know from other COPD studies that anxiety is able to increase dyspnoea, especially its qualitative dimensions, rather than its intensity $[48,49]$. Finally, COPD studies (nothing in $\mathrm{PH}$ ) have clearly demonstrated the salutary effects of pulmonary rehabilitation on anxiety, dyspnoea [50] and less consistently on dynamic hyperinflation [48]. It would be interesting to evaluate the effects of anxiolytic treatment on breathing pattern profile and dynamic hyperinflation and exertional dyspnoea in future studies.

\section{Conclusions}

This study demonstrates the importance of constraints on $V_{\mathrm{T}}$ expansion on dyspnoea intensity and quality during exercise in patients with $\mathrm{PH}$, irrespective of aetiology. Specifically, the inflection point in $V_{\mathrm{T}}$ relative to $V_{\mathrm{E}}^{\prime}$ marked the onset of a large increase in dyspnoea intensity and an increase in the selection frequency of unsatisfied inspiration as the predominant dyspnoea descriptor. In the affective domain, the emotion most frequently associated with this dyspnoea descriptor was, clearly, anxiety.

Interventions that reduce ventilatory demand and therefore delay or prevent an inflection in tidal volume relative to ventilation from occurring should reduce dyspnoea intensity and the highly anxiogenic perception of unsatisfied inspiration in this population.

Author contributions: All authors played a role in the content and writing of the manuscript. In addition: conception and design: P. Laveneziana, A. Boucly, O. Sitbon; analysis and interpretation: P. Laveneziana, A. Boucly, T. Similowski, O. Sitbon; drafting and revising the manuscript for important intellectual content: all authors.

Conflict of interest: A. Boucly reports personal fees and non-financial support from Actelion Pharmaceuticals and Merck, non-financial support from Bayer HealthCare and GlaxoSmithKline, outside the submitted work. C. Morélot-Panzini reports personal fees from AstraZeneca, Chiesi, Boehringer Ingelheim, Novartis, Philips, ADEP and SOS Oxygene, outside the submitted work. G. Garcia has nothing to disclose. J. Weatherald has nothing to disclose. $\mathrm{X}$. Jaïs reports grants, personal fees and non-financial support from Actelion Pharmaceuticals, Bayer HealthCare, GlaxoSmithKline and MSD, outside the submitted work. L. Savale reports grants and personal fees from Actelion Pharmaceuticals and Bayer HealthCare, personal fees from GlaxoSmithKline and Merck, outside the submitted work. D. Montani reports grants and personal fees from Actelion Pharmaceuticals and Bayer HealthCare, personal fees from GlaxoSmithKline, Novartis, Pfizer and BMS, outside the submitted work. M. Humbert has relationships with drug companies including Actelion, Bayer, GSK, Merck and United Therapeutics; in addition to being investigator in trials involving these companies, relationships include consultancy services and membership of scientific advisory boards. T. Similowski reports personal fees from AstraZeneca, Boehringer Ingelheim France, GSK, Lungpacer Inc., TEVA, Chiesi and Invacare, personal fees and non-financial support from Novartis, outside the submitted work. O. Sitbon reports grants, personal fees and non-financial support from Actelion Pharmaceuticals and GlaxoSmithKline, personal fees from Acceleron Pharmaceuticals, Arena Pharmaceuticals and Gossamer Bio, grants and personal fees from Bayer HealthCare and Merck, outside the submitted work. P. Laveneziana reports personal fees from Novartis France and Boehringer France, outside the submitted work.

Support statement: This study formed the basis of Athénaïs Boucly's Master 2 degree, which was funded by the "Fondation pour la Recherche Médicale" (DEA20150633823).

\section{References}

1 Laviolette L, Laveneziana P. Dyspnoea: a multidimensional and multidisciplinary approach. Eur Respir J 2014; 43: $1750-1762$. 
2 Galiè N, Humbert M, Vachiery JL, et al. 2015 ESC/ERS Guidelines for the diagnosis and treatment of pulmonary hypertension: the joint task force for the diagnosis and treatment of pulmonary hypertension of the European Society of Cardiology (ESC) and the European Respiratory Society (ERS): Endorsed by: Association for European Paediatric and Congenital Cardiology (AEPC), International Society for Heart and Lung Transplantation (ISHLT). Eur Heart J 2016; 37: 67-119.

3 Parshall MB, Schwartzstein RM, Adams L, et al. An official American Thoracic Society statement: update on the mechanisms, assessment, and management of dyspnea. Am J Respir Crit Care Med 2012; 185: 435-452.

4 Sun XG, Hansen JE, Oudiz RJ, et al. Exercise pathophysiology in patients with primary pulmonary hypertension. Circulation 2001; 104: 429-435.

5 Arena R, Guazzi M, Myers J, et al. Cardiopulmonary exercise testing in the assessment of pulmonary hypertension. Expert Rev Respir Med 2011; 5: 281-293.

6 Sajkov D, Petrovsky N, Palange P. Management of dyspnea in advanced pulmonary arterial hypertension. Curr Opin Support Palliat Care 2010; 4: 76-84.

7 Richter MJ, Voswinckel R, Tiede $\mathrm{H}$, et al. Dynamic hyperinflation during exercise in patients with precapillary pulmonary hypertension. Respir Med 2012; 106: 308-313.

8 Laveneziana P, Garcia G, Joureau B, et al. Dynamic respiratory mechanics and exertional dyspnoea in pulmonary arterial hypertension. Eur Respir J 2013; 41: 578-587.

9 Laveneziana P, Humbert M, Godinas L, et al. Inspiratory muscle function, dynamic hyperinflation and exertional dyspnoea in pulmonary arterial hypertension. Eur Respir J 2015; 45: 1495-1498.

10 Laveneziana P, Bruni GI, Presi I, et al. Tidal volume inflection and its sensory consequences during exercise in patients with stable asthma. Respir Physiol Neurobiol 2013; 185: 374-379.

11 Laveneziana P, Webb KA, Ora J, et al. Evolution of dyspnea during exercise in chronic obstructive pulmonary disease: impact of critical volume constraints. Am J Respir Crit Care Med 2011; 184: 1367-1373.

12 Guenette JA, Webb KA, O'Donnell DE. Does dynamic hyperinflation contribute to dyspnoea during exercise in patients with COPD? Eur Respir J 2012; 40: 322-329.

13 Laveneziana P, Lotti P, Coli C, et al. Mechanisms of dyspnoea and its language in patients with asthma. Eur Respir J 2006; 27: 742-747.

14 O'Donnell DE, Bertley JC, Chau LK, et al. Qualitative aspects of exertional breathlessness in chronic airflow limitation: pathophysiologic mechanisms. Am J Respir Crit Care Med 1997; 155: 109-115.

15 O'Donnell DE, Chau LK, Webb KA. Qualitative aspects of exertional dyspnea in patients with interstitial lung disease. J Appl Physiol 1998; 84: 2000-2009.

16 Laveneziana P, Webb KA, Wadell K, et al. Does expiratory muscle activity influence dynamic hyperinflation and exertional dyspnea in COPD? Respir Physiol Neurobiol 2014; 199: 24-33.

17 O'Donnell DE, Guenette JA, Maltais F, et al. Decline of resting inspiratory capacity in COPD: the impact on breathing pattern, dyspnea, and ventilatory capacity during exercise. Chest 2012; 141: 753-762.

18 O'Donnell DE, Hamilton AL, Webb KA. Sensory-mechanical relationships during high-intensity, constant-work-rate exercise in COPD. J Appl Physiol 2006; 101: 1025-1035.

19 di Paco A, Dubé BP, Laveneziana P. Changes in ventilatory response to exercise in trained athletes: respiratory physiological benefits beyond cardiovascular performance. Arch Bronconeumol 2017; 53: 237-244.

20 Banzett RB, Pedersen SH, Schwartzstein RM, et al. The affective dimension of laboratory dyspnea: air hunger is more unpleasant than work/effort. Am J Respir Crit Care Med 2008; 177: 1384-1390.

21 Simonneau G, Montani D, Celermajer DS, et al. Haemodynamic definitions and updated clinical classification of pulmonary hypertension. Eur Respir J 2019; 53: 1801913.

22 Badesch DB, Champion HC, Sanchez MA, et al. Diagnosis and assessment of pulmonary arterial hypertension. J Am Coll Cardiol 2009; 54: S55-S66.

23 Galiè N, Hoeper MM, Humbert M, et al. Guidelines for the diagnosis and treatment of pulmonary hypertension. Eur Respir J 2009; 34: 1219-1263.

24 Pellegrino R, Viegi G, Brusasco V, et al. Interpretative strategies for lung function tests. Eur Respir J 2005; 26: 948-968.

25 Kovacs G, Herve P, Barbera JA, et al. An official European Respiratory Society statement: pulmonary haemodynamics during exercise. Eur Respir J 2017; 50: 1700578.

26 Puente-Maestu L, Palange P, Casaburi R, et al. Use of exercise testing in the evaluation of interventional efficacy: an official ERS statement. Eur Respir J 2016; 47: 429-460.

27 Miller MR, Hankinson J, Brusasco V, et al. Standardisation of spirometry. Eur Respir J 2005; 26: 319-338.

28 Wanger J, Clausen JL, Coates A, et al. Standardisation of the measurement of lung volumes. Eur Respir J 2005; 26 : 511-522.

29 Macintyre N, Crapo RO, Viegi G, et al. Standardisation of the single-breath determination of carbon monoxide uptake in the lung. Eur Respir J 2005; 26: 720-735.

30 Quanjer PH, Tammeling GJ, Cotes JE, et al. Lung volumes and forced ventilatory flows. Report Working Party Standardization of Lung Function Tests, European Community for Steel and Coal. Official statement of the European Respiratory Society. Eur Respir J Suppl 1993; 16: 5-40.

31 Borg GA. Psychophysical bases of perceived exertion. Med Sci Sports Exerc 1982; 14: 377-381.

32 Lau EMT, Chemla D, Godinas L, et al. Loss of vascular distensibility during exercise is an early hemodynamic marker of pulmonary vascular disease. Chest 2016; 149: 353-361.

33 Banzett RB, O'Donnell CR, Guilfoyle TE, et al. Multidimensional Dyspnea Profile: an instrument for clinical and laboratory research. Eur Respir J 2015; 45: 1681-1691.

34 Morélot-Panzini C, Gilet H, Aguilaniu B, et al. Real-life assessment of the multidimensional nature of dyspnoea in COPD outpatients. Eur Respir J 2016; 47: 1668-1679.

35 Bechbache RR, Chow HHK, Duffin J, et al. The effects of hypercapnia, hypoxia, exercise and anxiety on the pattern of breathing in man. J Physiol 1979; 293: 285-300.

36 Gallagher CG, Brown E, Younes M. Breathing pattern during maximal exercise and during submaximal exercise with hypercapnia. J Appl Physiol 1987; 63: 238-244.

37 Hey EN, Lloyd BB, Cunningham DJ, et al. Effects of various respiratory stimuli on the depth and frequency of breathing in man. Respir Physiol 1966; 1: 193-205. 
Milic-Emili G, Cajani F. La frequenza dei respiri in funzione della ventilazione durante la marcia [Frequency of breathing as a function of ventilation during a march]. Boll Soc Ital Biol Sper 1957; 33: 825-827.

39 Laveneziana P, O’Donnell DE, Ofir D, et al. Effect of biventricular pacing on ventilatory and perceptual responses to exercise in patients with stable chronic heart failure. J Appl Physiol 2009; 106: 1574-1583.

40 Richter MJ, Gall H, Wittkämper G, et al. Inspiratory capacity is not altered in operable chronic thromboembolic pulmonary hypertension. Pulm Circ 2017; 7: 543-546.

41 Smith JR, Johnson BD, Olson TP. Impaired central hemodynamics in chronic obstructive pulmonary disease during submaximal exercise. J Appl Physiol 2019; 127: 691-697.

42 Laveneziana P, Di Paolo M. Exploring cardiopulmonary interactions during constant-workload submaximal cycle exercise in COPD patients. J Appl Physiol 2019; 127: 688-690.

43 Tello K, Dalmer A, Vanderpool R, et al. Impaired right ventricular lusitropy is associated with ventilatory inefficiency in PAH. Eur Respir J 2019; 54: 1900342.

44 Campbell EJ, Howell JB. The sensation of breathlessness. Br Med Bull 1963; 19: 36-40.

45 Georges M, Golmard JL, Llontop C, et al. Initiation of non-invasive ventilation in amyotrophic lateral sclerosis and clinical practice guidelines: single-centre, retrospective, descriptive study in a national reference centre. Amyotroph Lateral Scler Frontotemporal Degener 2017; 18: 46-52.

46 Similowski T. Treat the lungs, fool the brain and appease the mind: towards holistic care of patients who suffer from chronic respiratory diseases. Eur Respir J 2018; 51: 1800316.

47 Minasian AG, van den Elshout FJ, Dekhuijzen PN, et al. Bronchodilator responsiveness in patients with chronic heart failure. Heart Lung 2013; 42: 208-214.

48 Wadell K, Webb KA, Preston ME, et al. Impact of pulmonary rehabilitation on the major dimensions of dyspnea in COPD. COPD 2013; 10: 425-435.

49 Carrieri-Kohlman V, Gormley JM, Douglas MK, et al. Exercise training decreases dyspnea and the distress and anxiety associated with it. Monitoring alone may be as effective as coaching. Chest 1996; 110: 1526-1535.

50 Janssens T, De Peuter S, Stans L, et al. Dyspnea perception in COPD: association between anxiety, dyspnea-related fear, and dyspnea in a pulmonary rehabilitation program. Chest 2011; 140: 618-625. 